\title{
Evaluation of factors affecting sexual dysfunction in female patients with diabetes mellitus
}

\author{
Mustafa Gürkan Yenice \\ https://orcid. org/0000-0002-5813-3565 \\ Yavuz Onur Danacıoğlu'
https://orcid. org/0000-0002-3170-062X \\ Meral Mert ${ }^{2}$ \\ https://orcid. org/0000-0003-3431-0915 \\ Pınar Karakaya ${ }^{2}$ \\ https://orcid. org/0000-0003-3638-5603 \\ Kamil Gokhan Seker ${ }^{3}$ \\ https://orcid.org/0000-0003-4449-9037 \\ Fatih Akkaş $^{3}$ \\ https://orcid. org/0000-0002-4560-7426
}

Abdulmuttalip Şimşek ${ }^{3}$

https://orcid.org/0000-0001-8003-4654

Selçuk Şahin ${ }^{3}$

https://orcid.org/0000-0002-0903-320X

Ali Ihsan Taşçi ${ }^{3}$

https://orcid. org/0000-0002-6943-6676

\begin{abstract}
Objective: Our objective in this study was to evaluate the factors predicting female sexual dysfunction (FSD) in patients with diabetes mellitus (DM). Subjects and methods: The study included 149 women with DM. Sexual function was evaluated with the Female Sexual Function Index (FSFI) questionnaire, in which total scores under 26.55 characterized the occurrence of FSD (Group $1>26.55$, Group 2 $<26.55)$. We recorded the patients' demographic, metabolic, and hormonal data. Ophthalmologic, neurologic, and renal complications were also evaluated. The antioxidant status of the patients in both groups was determined by measuring the activity of the enzymes paraoxonase-1 (PON-1) and arylesterase (ARE). Results: Based on the FSFI scores, 60 patients were allocated to Group 1 (26.6 \pm 12.3 ) and 89 to Group $2(22.6 \pm 9.5)$. Group 2 compared with Group 1 had significantly $(p<0.05)$ higher mean concentrations of glycated hemoglobin ( $\mathrm{HbA} 1 \mathrm{c})$, glucose, triglycerides, and insulin, along with higher rates of metformin use, smoking, retinopathy, and nephropathy. The mean serum ARE concentrations were significantly lower in Group 2 compared with Group $1(p=0.000)$, but the mean serum PON-1 concentrations were similar between both groups $(p=0.218)$. On multivariable regression analysis, age, ARE activity, Beck Depression Inventory (BDI) score, and menopause were significant independent predictors of FSD $(p<0.05)$. Conclusions: In this study, we evaluated the predictive factors determining FSD caused by DM. Despite the significant results found in our study, future randomized controlled studies with a long follow-up and a larger number of patients are required to determine how DM affects FSD. Arch Endocrinol Metab. 2020;64(3):319-25
\end{abstract}

Keywords

Arylesterase; diabetes mellitus; endocrine disorder; female sexual dysfunction; paraoxonase-1
${ }^{1}$ Clinic of Urology, University of Health Sciences, Bakırköy Dr. Sadi Konuk Training and Research Hospital, Istanbul, Turkey

2 Department of Endocrinology, University of Health Sciences, Bakırköy Dr. Sadi Konuk Training and Research Hospital, Istanbul, Turkey ${ }^{3}$ Clinic of Urology, University of Health Sciences, Bakırköy Dr. Sadi Konuk Training and Research Hospital, Istanbul, Turkey
Correspondence to:

Yavuz Onur Danacıoğlu Bakirkoy Dr.Sadi Konuk

Education and Research Hospital

Department of Urology

Tevfik Saglam Caddesi No:11

Zuhuratbaba/Bakirkoy

34147 - Istanbul, Turkey

yavuzonurd@gmail.com

Received on Oct/23/2019

Accepted on Feb/3/2020

DOI: $10.20945 / 2359-3997000000238$

\section{INTRODUCTION}

$\mathrm{D}$ iabetes mellitus (DM) is one of the most common noninfectious progressive and chronic diseases worldwide, constituting an important current health problem (1). The prevalence of type $2 \mathrm{DM}$ is increasing at a fast pace in developed and developing countries due to lifestyle changes. The 2017 International Diabetes Federation (IDF) DM map predicted that 425 million people worldwide had type $2 \mathrm{DM}$, and that this number will reach nearly 630 million with a $48 \%$ increase by 2045 (2). Microvascular and macrovascular complications of DM lead to loss of function in many organs and systems. 
In the long term, DM causes complications such as chronic renal disease, peripheral neuropathy, retinopathy, and cardiovascular disorders (3). Sexual dysfunction may affect both sexes due to vascular, psychogenic, and neurogenic disorders caused by DM (4). Until recently, sexual dysfunction in patients with DM was attributed to psychogenic factors (5). Due to cultural and ethnic causes, sexual dysfunction caused by DM can be overlooked in women. In published studies, sexual function disorder is more often investigated in men and considered less important in women. Thus, the etiology of DM-associated female sexual dysfunction (FSD) and its risk factors are still controversial. The literature reports FSD as occurring more frequently in postmenopausal women, at a prevalence of $40-60 \%$ (6). Also, a higher prevalence of FSD is seen in women with both types (1 and 2) DM compared with nondiabetic normal women $(7,8)$.

Multifactorial causes due to hyperglycemia, infection, vascular, neurogenic, and psychogenic factors lead to sexual dysfunction in women with diabetes. Systemic adverse events caused by diabetes lead to vaginal and clitoral hemodynamic deterioration, lubrication problems, decreased genital muscle activity, and loss of sensitivity in the genital area $(3,9)$. Diabetes duration, poor glycemic control, advanced age, presence of complications, low-quality partner relationships, and poor cognitive adjustment have been previously defined as predictors of FSD (8). Also, the relationship between FSD and obesity, metabolic syndrome, and microvascular complications has been emphasized in recent studies (6).

In the present study, our objective was to determine psychogenic and organic predictive factors causing FSD in women with DM presenting with symptoms of sexual dysfunction.

\section{SUBJECTS AND METHODS}

The study protocol was approved by the local ethics committee at Bakirkoy Dr. Sadi Konuk Training and Research Hospital, and the study was conducted according to the Declaration of Helsinki. All subjects were informed about the study protocol, and written consents were obtained. This prospective clinical trial was conducted between January and December 2018.

A total of 149 women with diabetes and prediabetes admitted to our outpatient diabetes clinic were enrolled in the study. All participants met the following inclusion criteria: minimum age of 18 years, no concomitant pathologies, no medication use (except for antidiabetic agents), no hormonal abnormalities (including folliclestimulating hormone, luteinizing hormone, prolactin, estradiol, and androgens), heterosexual status, absence of sexual disorder in the male partner, and steady relationship for at least 1 year. The exclusion criteria were pregnancy or post-partum, chronic illness, diagnosis of psychiatric disorder, and use of hormonal contraception.

The Female Sexual Function Index (FSFI) questionnaire was used to evaluate sexual functioning, and the Beck Depression Inventory (BDI) was used to evaluate depression severity. Both questionnaires were self-filled by each patient. The FSFI is a self-reported form that includes 19 items measuring female sexual functioning. This questionnaire addresses desire, arousal, lubrication, orgasm, satisfaction, and pain under six main headings. Total FSFI scores below 26 categorized FSD in the present study (10). The BDI is a self-evaluation scale with 21 items applied to measure physical, emotional, and cognitive symptoms present in depression. Total BDI scores were regarded as indicating mild depression when between 10-18, moderate depression when between 19-29, and severe depression when $>30$ (11). Based on FSFI scores, the patients were categorized into Group 1 (scores > $26.55)$ and Group 2 (scores < 26.55).

Each patient underwent a physical and genitourinary examination. Age, body mass index (BMI), parity, comorbid disorders (hypertension), use of oral antidiabetic agent (metformin) and insulin, smoking and alcohol use, and menopause duration were recorded for each patient.

Blood samples were collected after 12-hour overnight fasting for measurement of routine biochemical tests, lipid profile, and levels of glycated hemoglobin (HbAlc), insulin, creatinine, thyroidstimulating hormone (TSH), free thyroxine (FT4), and free triiodothyronine (FT3). Nephropathy, retinopathy, polyneuropathy, and hypertension were diagnosed based on medical history, physical examination, and laboratory findings. Patients with a mean blood pressure level $\geq 140 / 90 \mathrm{mmHg}$ and those on antihypertensive medications were classified as hypertensive. Eye complications were defined as the presence of cataract or any grade of diabetic retinopathy or maculopathy on dilated eye examination. Renal complications included microalbuminuria or macroalbuminuria. The 
Diabetic Neuropathy Index, which detects somatic and autonomic neuropathy, was used to assess the presence of diabetic neuropathy.

A novel method was used to determine paraoxonase-1 (PON-1) and arylesterase (ARE) activity levels (12). Briefly, the paraoxon hydrolysis (diethyl-p-nitrophenylphosphate) rate was determined by measuring the increase in absorbance at $412 \mathrm{~nm}$ and $25{ }^{\circ} \mathrm{C}$. PON-1 activity is expressed as units per liter (U/L) of serum. Using spectrophotometry, ARE activity was measured using phenylacetate as a substrate. The reaction was started by the addition of the serum and measured by the absorbance increase at $270 \mathrm{~nm}$. Enzymatic activity was calculated from the molar absorptivity coefficient of the produced phenol. One unit of ARE activity was defined as $1 \mu \mathrm{mol}$ of phenol generated per minute under the defined assay conditions and is also expressed as $\mathrm{U} / \mathrm{L}$ (13).

\section{Statistical analysis}

The data are described as rates and mean, standard deviation, median, minimum and maximum, and frequency values. The Kolmogorov-Smirnov test was used to analyze the distribution of the variables. Student's $t$ test and Mann-Whitney U test were used to analyze independent quantitative data, while the chisquare test was used to analyze independent qualitative data. The effect level was investigated using univariate and multivariate logistic regression. The SPSS 22.0 statistics software (IBM Corp., Armonk, NY, USA) was used for the analyses.

\section{RESULTS}

The baseline characteristics of all 149 women are summarized in Table 1. Based on the FSFI scores, 60 patients were allocated to Group 1 and 89 patients to Group 2. The mean total FSFI score was significantly lower in Group $2(22.6 \pm 9.5)$ compared with Group 1 $(26.6 \pm 12.3 ; \mathrm{p}=0.012)$. The mean diabetes duration was $11.1 \pm 6.6$ years, the mean glucose value was 147.3 $\pm 60.4 \mathrm{mg} / \mathrm{dL}$, and the mean $\mathrm{HbAlc}$ value was 7.2 $\pm 1.8 \%$. The mean age of the women in Groups 1 and 2 was $50.1 \pm 13.0$ years and $53.2 \pm 13.2$ years, respectively. The mean ages of the participants in both groups were similar $(\mathrm{p}=0.154)$. Mean BMI was also similar between Groups 1 and $2\left(31.7 \pm 5.3 \mathrm{~kg} / \mathrm{m}^{2}\right.$ and $29.6 \pm 5.8 \mathrm{~kg} / \mathrm{m}^{2}$, respectively; $\left.\mathrm{p}=0.030\right)$. The mean BDI score was higher in Group $2(15.9 \pm 8.2)$ compared with Group $1(10.1 \pm 7.3 ; \mathrm{p}=0.000)$. The mean TSH concentration was also significantly lower in Group 2 compared with Group $1(2.4 \pm 1.8 \mathrm{mU} / \mathrm{L}$ versus $4.0 \pm$ $2.8 \mathrm{mU} / \mathrm{L}$, respectively; $\mathrm{p}=0.07$ ).

The mean concentrations of HbAlc, glucose, triglycerides, and insulin, as well as the rates of metformin use, smoking, retinopathy, and nephropathy, were significantly higher in Group 2 than Group 1 $(\mathrm{p}<0.05)$. Groups 1 and 2 showed no differences in regard to levels of creatine, FT4, hemoglobin, highdensity lipoprotein (HDL), low-density lipoprotein

Table 1. Demographic and clinical data of the participants

\begin{tabular}{|c|c|c|c|c|}
\hline & Min & Max & Median & $\begin{array}{c}\text { Mean } \pm \text { SD/ } \\
n(\%)\end{array}$ \\
\hline Age (years) & 19.0 & 83.0 & 52.0 & $52.0 \pm 13.2$ \\
\hline BMI $\left(\mathrm{kg} / \mathrm{m}^{2}\right)$ & 19.0 & 48.0 & 30.0 & $30.5 \pm 5.7$ \\
\hline DM duration (years) & 1.0 & 36.0 & 9.0 & $11.1 \pm 6.6$ \\
\hline Parity (n) & 0.0 & 13.0 & 2.0 & $2.4 \pm 2.3$ \\
\hline HbA1c (\%) & 2.0 & 15.8 & 6.8 & $7.2 \pm 1.8$ \\
\hline Glucose (mg/dL) & 82.0 & 389.0 & 126.0 & $147.3 \pm 60.4$ \\
\hline Creatinine (mg/dL) & 0.2 & 37.0 & 0.6 & $0.9 \pm 3.0$ \\
\hline TSH (mU/L) & 0.0 & 10.3 & 2.0 & $3.0 \pm 2.4$ \\
\hline $\mathrm{FT} 4$ (mU/L) & 0.1 & 1.9 & 0.9 & $0.9 \pm 0.2$ \\
\hline $\operatorname{Hgb}(g / d L)$ & 7.4 & 16.0 & 12.5 & $12.4 \pm 1.3$ \\
\hline $\mathrm{HDL}(\mathrm{mg} / \mathrm{dL})$ & 24.0 & 87.0 & 48.0 & $49.0 \pm 10.3$ \\
\hline LDL (mg/dL) & 11.0 & 275.0 & 125.5 & $127.0 \pm 38.0$ \\
\hline Total cholesterol (mg/dL) & 127.0 & 325.0 & 198.0 & $204.9 \pm 42.1$ \\
\hline Triglycerides (mg/dL) & 48.0 & 477.0 & 135.0 & $152.4 \pm 74.4$ \\
\hline PON-1 (U/L) & 46.6 & 262.0 & 117.2 & $121.5 \pm 38.7$ \\
\hline ARE (U/L) & 90.8 & 279.2 & 149.0 & $152.2 \pm 41.5$ \\
\hline Insulin use & & & & $51 \quad 34.0 \%$ \\
\hline Metformin use & & & & $59 \quad 39.3 \%$ \\
\hline Smoking & & & & $14 \quad 9.3 \%$ \\
\hline Alcohol use & & & & $14 \quad 9.3 \%$ \\
\hline Menopause & & & & $65 \quad 43.3 \%$ \\
\hline Duration of menopause & 2.0 & 40.0 & 12.0 & $12.7 \pm 7.7$ \\
\hline Retinopathy & & & & $14 \quad 9.3 \%$ \\
\hline Neuropathy & & & & $27 \quad 18.0 \%$ \\
\hline Nephropathy & & & & $9 \quad 6.0 \%$ \\
\hline Hypertension & & & & $71 \quad 47.3 \%$ \\
\hline BDI & 2.0 & 40.0 & 11.5 & $13.6 \pm 8.3$ \\
\hline FSFI & 2.0 & 76.0 & 26.5 & $24.2 \pm 10.8$ \\
\hline Sexual dysfunction & & & & $70 \quad 46.7 \%$ \\
\hline
\end{tabular}

Min-Max: minimum-maximum; SD: Standard deviation; BMl: body mass index; DM: diabetes mellitus; HbA1c: glycated hemoglobin; TSH: thyroid-stimulating hormone; FT4: free thyroxine; Hgb: hemoglobin; HDL: high-density lipoprotein; LDL: low-density lipoprotein; PON-1: paraoxonase-1; ARE: arylesterase; BDI: Beck Depression Inventory; FSFI: Female Sexual Functioning Index. 
(LDL), and total cholesterol, or in terms of duration of alcohol use and rates and duration of menopause and hypertension $(\mathrm{p}>0.05)$. The mean serum ARE concentrations were lower in Group 2 (138.7 \pm 33.0 $\mathrm{U} / \mathrm{L})$ compared with Group $\mathrm{l}(172.7 \pm 44.8 ; \mathrm{p}=$ 0.000 ), but no significant difference was observed in mean serum PON-1 concentrations between both groups $(118.1 \pm 35.7$ versus $126.7 \pm 42.7$, respectively, $\mathrm{p}=0.218)($ Table 2$)$.

Age; parity; values of $\mathrm{HbAlc}$, creatinine, $\mathrm{TSH}$, and triglycerides; ARE activity; BDI scores; and rates of insulin use, menopause, nephropathy, and hypertension emerged as significant predictors of diabetic FSD on univariate regression analysis $(\mathrm{p}<0.05)$. On multivariate regression analysis, age, ARE activity, BDI, and menopause remained as significant independent predictors of FSD $(\mathrm{p}<0.05)$ (Table 3$)$.

\section{DISCUSSION}

The World Health Organization (WHO) declared human sexuality to be part of health quality and wellbeing in 1974. In women, sexual function depends on different physiological circumstances such as vaginal hemodynamics and neurologic innervation, and the activity of genital and pelvic structures $(3,14)$. Sexual

Table 2. Comparison of the general characteristics and biochemical studies

\begin{tabular}{|c|c|c|c|c|c|c|c|}
\hline & \multicolumn{3}{|c|}{ Group 1} & \multicolumn{3}{|c|}{ Group 2} & \multirow{2}{*}{$p$ value } \\
\hline & \multicolumn{2}{|c|}{ Mean \pm SD/n (\%) } & Median & \multicolumn{2}{|c|}{ Mean \pm SD/n (\%) } & Median & \\
\hline Age (years) & \multicolumn{2}{|c|}{$50.1 \pm 13.0$} & 50.0 & \multicolumn{2}{|c|}{$53.2 \pm 13.2$} & 54.5 & $0.154^{t}$ \\
\hline BMI $\left(\mathrm{kg} / \mathrm{m}^{2}\right)$ & \multicolumn{2}{|c|}{$31.7 \pm 5.3$} & 30.5 & \multicolumn{2}{|c|}{$29.6 \pm 5.8$} & 29.0 & $0.030^{\mathrm{m}}$ \\
\hline Parity (n) & \multicolumn{2}{|c|}{$2.7 \pm 2.3$} & 2.0 & \multicolumn{2}{|c|}{$2.3 \pm 2.4$} & 2.0 & $0.148^{m}$ \\
\hline HbA1c (\%) & \multicolumn{2}{|c|}{$6.4 \pm 1.0$} & 6.2 & \multicolumn{2}{|c|}{$7.7 \pm 2.0$} & 7.4 & $0.000^{\mathrm{m}}$ \\
\hline Glucose (mg/dL) & \multicolumn{2}{|c|}{$111.5 \pm 14.2$} & 112.0 & \multicolumn{2}{|c|}{$171.1 \pm 67.4$} & 148.5 & $0.000^{\mathrm{m}}$ \\
\hline Creatinine (mg/dL) & \multicolumn{2}{|c|}{$1.2 \pm 4.7$} & 0.6 & \multicolumn{2}{|c|}{$0.7 \pm 0.5$} & 0.6 & $0.061^{m}$ \\
\hline TSH (mU/L) & \multicolumn{2}{|c|}{$4.0 \pm 2.8$} & 3.2 & \multicolumn{2}{|c|}{$2.4 \pm 1.8$} & 1.9 & $0.007^{\mathrm{m}}$ \\
\hline FT4 (mU/L) & \multicolumn{2}{|c|}{$0.9 \pm 0.2$} & 0.9 & \multicolumn{2}{|c|}{$1.0 \pm 0.2$} & 1.0 & $0.059 \mathrm{~m}$ \\
\hline $\mathrm{Hgb}(\mathrm{g} / \mathrm{dL})$ & \multicolumn{2}{|c|}{$12.3 \pm 0.9$} & 12.5 & \multicolumn{2}{|c|}{$12.4 \pm 1.4$} & 12.6 & $0.574^{m}$ \\
\hline HDL (mg/dL) & \multicolumn{2}{|c|}{$48.5 \pm 9.6$} & 48.0 & \multicolumn{2}{|c|}{$49.3 \pm 10.8$} & 49.5 & $0.864^{m}$ \\
\hline LDL (mg/dL) & \multicolumn{2}{|c|}{$130.0 \pm 33.3$} & 126.5 & \multicolumn{2}{|c|}{$125.0 \pm 40.8$} & 121.5 & $0.482^{m}$ \\
\hline Total cholesterol (mg/dL) & \multicolumn{2}{|c|}{$205.6 \pm 37.8$} & 196.5 & \multicolumn{2}{|c|}{$204.4 \pm 45.0$} & 200.0 & $0.168^{m}$ \\
\hline Triglycerides (mg/dL) & \multicolumn{2}{|c|}{$125.2 \pm 49.4$} & 114.0 & 170 & \pm 82.5 & 153.0 & $0.000^{\mathrm{m}}$ \\
\hline PON-1 (U/L) & 126 & \pm 42.7 & 122.6 & 118 & \pm 35.7 & 109.9 & $0.218^{m}$ \\
\hline ARE (U/L) & & \pm 44.8 & 185.9 & 138 & \pm 33.0 & 130.5 & $0.000^{\mathrm{m}}$ \\
\hline Insulin use & 0 & $0.0 \%$ & & 51 & $56.7 \%$ & & $0.000^{x^{2}}$ \\
\hline Metformin use & 0 & $0.0 \%$ & & 59 & $65.6 \%$ & & $0.000^{x^{2}}$ \\
\hline Smoking & 0 & $0.0 \%$ & & 14 & $15.6 \%$ & & $0.001^{x^{2}}$ \\
\hline Alcohol use & 4 & $6.7 \%$ & & 10 & $11.1 \%$ & & $0.359 x^{2}$ \\
\hline Menopause & 26 & $43.3 \%$ & & 39 & $43.3 \%$ & & $1.000 x^{2}$ \\
\hline Menopause duration & & \pm 8.0 & 12.0 & & \pm 7.5 & 14.0 & $0.321^{\mathrm{m}}$ \\
\hline Retinopathy & 0 & $0.0 \%$ & & 14 & $15.6 \%$ & & $0.001^{x^{2}}$ \\
\hline Neuropathy & 0 & $0.0 \%$ & & 27 & $30.0 \%$ & & $0.000^{x^{2}}$ \\
\hline Nephropathy & 0 & $0.0 \%$ & & 9 & $10.0 \%$ & & $0.012^{x^{2}}$ \\
\hline Hypertension & 23 & $38.3 \%$ & & 48 & $53.3 \%$ & & $0.071^{x^{2}}$ \\
\hline $\mathrm{BDI}$ & & \pm 7.3 & 8.0 & & \pm 8.2 & 14.0 & $0.000^{\mathrm{m}}$ \\
\hline FSFI & & \pm 12.3 & 29.0 & & \pm 9.5 & 24.5 & $0.012^{m}$ \\
\hline Sexual dysfunction & 20 & $33.3 \%$ & & 50 & $55.6 \%$ & & $0.008^{x^{2}}$ \\
\hline
\end{tabular}

${ }^{\text {t}}$ Student's t test; ${ }^{m}$ Mann-Withney U test; ${ }^{2}{ }^{2}$ chi-square test. Abbreviations - Min-Max: minimummaximum; SD: Standard deviation; BMI: body mass index; DM: diabetes mellitus; HbA1c: glycated hemoglobin; TSH: thyroid-stimulating hormone; FT4: free thyroxine; Hgb: hemoglobin; HDL: highdensity lipoprotein; LDL: low-density lipoprotein; PON-1: paraoxonase-1; ARE: arylesterase; BDI: Beck Depression Inventory; FSFI: Female Sexual Functioning Index. 
disorders in patients with DM are related to psychological problems occurring due to medications or vascular and neuroendocrine complications of the disease (15).

Sexual dysfunction in female patients with DM occurs both due to decreased clitoral blood flow related to deterioration in the hypogastric-vaginal/clitoral arterial bed, which is part of vascular impairment and concurring peripheral neuropathy in DM. Despite this information, the number of studies determining the predisposing factors causing sexual dysfunction in women with diabetes is limited, and these studies generally have an inadequate number of patients and concentrate on specific factors $(2,16)$. We hypothesized that sexual dysfunction was related to organic and psychogenic causes in women with diabetes. Thus, our study investigated the psychogenic and underlying organic causes of FSD in a large patient population.
In our study, BDI scores were higher in patients with sexual dysfunction with low FSFI scores. Studies have shown that many psychological diseases, especially depression, cause sexual dysfunction in patients with diabetes. Both BDI scores and rates of sexual dysfunction have been reported to be higher in diabetic patients with complications compared with those without complications (17). BDI was shown to be an independent indicator of FSD in patients with DM in our study. Apart from psychogenic factors, organic causes occurring due to end-organ damage caused by diabetes also affect the sexual quality of life in women (18). Sexual activity and sexual satisfaction decrease in the presence of end-organ complications such as retinopathy, neuropathy, nephropathy, and heart disease in women with diabetes (19). In our study, the rates of nephropathy, neuropathy, and retinopathy were higher

Table 3. Univariate and multivariate logistic regression analyses

\begin{tabular}{|c|c|c|c|c|c|c|c|}
\hline & \multicolumn{3}{|c|}{ Univariate analysis } & \multicolumn{4}{|c|}{ Multivariate analysis } \\
\hline & OR & $95 \% \mathrm{Cl}$ & $p$ value & OR & $95 \%$ & CI & p value \\
\hline Age (years) & 1.19 & $1.13-1.26$ & 0.000 & 1.27 & 1.15 & 1.41 & 0.000 \\
\hline BMI $\left(\mathrm{kg} / \mathrm{m}^{2}\right)$ & 0.97 & $0.92-1.03$ & 0.313 & & & & \\
\hline Parity (n) & 1.19 & $1.02-1.38$ & 0.023 & & & & \\
\hline HbA1c (\%) & 1.27 & $1.04-1.55$ & 0.019 & & & & \\
\hline Glucose (mg/dL) & 1.00 & $1.00-1.01$ & 0.115 & & & & \\
\hline Creatinine (mg/dL) & 82.97 & $8.35->100$ & 0.000 & & & & \\
\hline TSH (mU/L) & 0.84 & $0.72-0.97$ & 0.019 & & & & \\
\hline FT4 (mU/L) & 1.63 & $0.38-7.01$ & 0.509 & & & & \\
\hline $\mathrm{Hgb}(\mathrm{g} / \mathrm{dL})$ & 1.04 & $0.81-1.34$ & 0.759 & & & & \\
\hline Total cholesterol (mg/dL) & 1.00 & $0.99-1.01$ & 0.513 & & & & \\
\hline $\mathrm{HDL}$ (mg/dL) & 0.99 & $0.96-1.02$ & 0.474 & & & & \\
\hline LDL (mg/dL) & 1.00 & $0.99-1.01$ & 0.897 & & & & \\
\hline Triglycerides (mg/dL) & 1.01 & $1.00-1.01$ & 0.003 & & & & \\
\hline PON-1 (U/L) & 0.99 & $0.98-1.00$ & 0.107 & & & & \\
\hline ARE (U/L) & 0.99 & $0.98-1.00$ & 0.023 & 0.99 & 0.97 & 1.00 & 0.018 \\
\hline BDI & 1.15 & $1.09-1.22$ & 0.000 & 1.11 & 1.04 & 1.19 & 0.002 \\
\hline Insulin use & 3.07 & $1.52-6.21$ & 0.002 & & & & \\
\hline Metformin use & 1.85 & $0.95-3.59$ & 0.068 & & & & \\
\hline Smoking & 0.84 & $0.28-2.56$ & 0.764 & & & & \\
\hline Alcohol use & 1.59 & $0.52-4.83$ & 0.412 & & & & \\
\hline Menopause & 4.75 & $2.37-9.53$ & 0.000 & 0.21 & 0.05 & 0.90 & 0.035 \\
\hline Retinopathy & 3.17 & $0.95-10.60$ & 0.061 & & & & \\
\hline Neuropathy & 2.25 & $0.95-5.30$ & 0.065 & & & & \\
\hline Nephropathy & 10.19 & $1.24-83.68$ & 0.031 & & & & \\
\hline Hypertension & 4.77 & $2.39-9.52$ & 0.000 & & & & \\
\hline
\end{tabular}

OR: odds ratio; Cl: confidence interval; BMI: body mass index; HbA1c: glycated hemoglobin; TSH: thyroid-stimulating hormone; FT4: free thyroxine; Hgb: hemoglobin; HDL: high-density lipoprotein LDL: Iow-density lipoprotein; PON-1: paraoxonase-1; ARE: arylesterase; BDI: Beck Depression Inventory. 
in patients with sexual dysfunction compared with those without this complication.

Blood vessel damage and clitoral nerve and autonomic nervous system degeneration are common in the genital organs of patients with diabetes, resulting in arousal and lubrication dysfunction $(7,15)$. In our study, patients with sexual dysfunction had higher triglycerides values and poor glycemic control. Low sexual desire and arousal have been reported in menopausal patients with metabolic syndrome and poor lipid profile in previous studies $(5,20,21)$. Several studies have also reported older age as a cause of sexual dysfunction in women $(22,23)$. In our study, we found that menopause and older age were independent indicators of sexual dysfunction based on multivariate analysis.

Vascular damage due to DM is one of the main causes of sexual dysfunction in both sexes. Increased lipids, glucose intolerance, and presence of metabolic syndrome induce vascular damage by potentializing the occurrence of atherosclerosis in these patients. One of the most important indicators of atherosclerosis in patients with types 1 and $2 \mathrm{DM}$ and metabolic syndrome is the occurrence of decreased PON and ARE enzyme activity $(24,25)$. PON is an ester hydrolase enzyme that can hydrolyze paraoxon, which is a strong inhibitor of cholinesterases. PON-1, PON-2, and PON-3 belong to a subgroup of enzymes in the PON gene family. Low serum PON-1 activity is associated with hyperlipidemia, type 1 DM, coronary artery disease, chronic kidney failure, rheumatoid arthritis, metabolic syndrome, uremia, and thyroid dysfunction (26).

PON- 1 and ARE are esterase group enzymes encoded by the same gene and with similar active centers. PON$l$ is an enzyme with three known main activities as paraoxonase, arylesterase, and dyazoxonase $(25,27,28)$. PON-1 and ARE contribute to the protective effect of HDL against atherosclerosis. A study by Ciftci and cols. observed a negative correlation between PON-1 activity and erectile dysfunction (ED), along with a correlation between PON-1 activity and HDL levels, while LDL levels were higher in the ED group compared with the control group (29). A study by Aldemir and cols. reported lower PON-1 and ARE activity in patients with ED compared with controls (28). In our study, PON-1 activity was lower in patients with FSD, but the difference was not statistically significant. In contrast, ARE activity was significantly lower in patients with FSD compared with those without FSD and emerged as an independent indicator of sexual activity in female patients with DM. Although the connection between PON and ARE activity and different diseases has been shown in many studies in literature, our study is the first to demonstrate the connection of FSD in women with DM with activity of the enzymes PON and ARE, both of which have antioxidant properties.

Our study has some limitations to take into consideration. The main one is the cross-sectional design. Also, the long-term effect of diabetes and related complications on sexual function was not investigated in our patients. The lack of data on lubrication and orgasm, both of which correlate with sexual desire in these patients and reflect vascular and neurologic deficit, hinders the presentation of more objective data. The sexual function of the patients in our study was considered to be normal based on the questions asked, but in our opinion, variations in sexual function between the partners may affect the patients' FSFI scores.

In conclusion, we showed that older age, ARE activity, BDI score, and menopause are independent risk factors for FSD in women with DM. The finding of diabetes causing sexual dysfunction due to psychogenic and organic causes is evidence that these patients should undergo a multidisciplinary evaluation. Sexual dysfunction is commonly neglected in patients with diabetes and should be investigated to improve their quality of life with treatment. In this study, we attempted to present the FSD factors that affect pathogenesis, but long-term randomized controlled studies are also needed to evaluate the changes caused by diabetesrelated complications on sexual dysfunction over time.

Ethical approval: all procedures involving human participants were in accordance with the ethical standards of the Bakırkoy Dr. Sadi Konuk Training and Research Hospital Clinical Research Ethics Committee and with the 1964 Helsinki Declaration and its later amendments or comparable ethical standards. This article does not contain any studies with animals performed by any of the authors.

Informed consent: informed consent was obtained from all individual participants included in the study.

Disclosure: no potential conflict of interest relevant to this article was reported.

\section{REFERENCES}

1. Shaw JE, Sicree RA, Zimmet PZ. Global estimates of the prevalence of diabetes for 2010 and 2030. Diabetes Res Clin Pract. 2010;87(1):4-14. 
2. Veyhe AS, Andreassen J, Halling J, Grandjean P, Petersen MS, Weihe P. Prevalence of prediabetes and type 2 diabetes in two non-random populations aged $44-77$ years in the Faroe Islands. J Clin Transl Endocrinol. 2019;16:100187.

3. Kizilay F, Gali HE, Serefoglu EC. Diabetes and sexuality. Sex Med Rev. 2017;5(1):45-51.

4. Duman NB. Frequency of sexual dysfunction and its causative factors among diabetic women in Turkey. Pak J Med Sci. 2014;30(3):558-63.

5. Yencilek F, Attar R, Erol B, Narin R, Aydın H, Karateke A, et al. Factors affecting sexual function in premenopausal age women with type 2 diabetes: a comprehensive study. Fertil Steril. 2010;94(5):1840-3.

6. Maiorino M, Bellastella G, Castaldo F, Petrizzo M, Giugliano D, Esposito K. Sexual function in young women with type 1 diabetes: the METRO study. J Endocrinol Invest. 2017;40(2):169-77.

7. Cortelazzi D, Marconi A, Guazzi M, Cristina M, Zecchini B, Veronelli A, et al. Sexual dysfunction in pre-menopausal diabetic women: clinical, metabolic, psychological, cardiovascular, and neurophysiologic correlates. Acta Diabetol. 2013;50(6):911-7.

8. Enzlin P, Mathieu C, Van den Bruel A, Vanderschueren D, Demyttenaere K. Prevalence and predictors of sexual dysfunction in patients with type 1 diabetes. Diabetes Care. 2003;26(2):409-14.

9. Marson L, Giamberardino MA, Costantini R, Czakanski P, Wesselmann $U$. Animal models for the study of female sexual dysfunction. Sex Med Rev. 2013;1(2):108-22.

10. Wiegel M, Meston C, Rosen R. The female sexual function index (FSFI): cross-validation and development of clinical cutoff scores. J Sex Marital Ther. 2005;31(1):1-20.

11. Beck AT, Rial WY, Rickels K. Short form of depression inventory: cross-validation. Psychol Rep. 1974;34(3):1184-6.

12. Ozturk E, Balat O, Dikensoy E, Ugur MG, Ozcan C, Aydin A, et al. No association between serum paraoxonase, arylesterase activities, and hydatidiform mole. Int J Gynecol Cancer. 2011;21(1):149-52.

13. OkuturlarY, Gedikbasi A, Akalin N, Gunaldi M, Yilmaz D, Mert M, et al. Serum paraoxonase 1 activity in patients with iron deficiency anemia. Arch Med Sci. 2016;12(4):697-703.

14. Sharifiaghdas F, Azadvari M, Shakhssalim N, Roohi-Gilani K, Rezaei-Hemami M. Female sexual dysfunction in type 2 diabetes: a case control study. Med Princ Pract. 2012;21(6):554-9.

15. Ismail AH, Bau R, Sidi H, Guan NC, Naing L, Jaafar NRN, et al. Factor analysis study on sexual responses in women with type 2 diabetes mellitus. Compr Psychiatry. 2014;55 Suppl 1:S34-7.
16. Kaya C, Yilmaz G, Nurkalem Z, Ilktac A, Karaman M. Sexual function in women with coronary artery disease: a preliminary study. Int J Impot Res. 2007;19(3):326-9.

17. Leedom L, Meehan WP, Procci W, Zeidler A. Symptoms of depression in patients with type II diabetes mellitus. Psychosomatics. 1991;32(3):280-6.

18. Pontiroli $A E$, Cortelazzi $D$, Morabito $A$. Female sexual dysfunction and diabetes: A systematic review and meta-analysis. J Sex Med. 2013;10(4):1044-51.

19. Copeland KL, Brown JS, Creasman JM, Van Den Eeden SK, Subak $\mathrm{LL}$, Thom DH, et al. Diabetes mellitus and sexual function in middleaged and older women. Obstet Gynecol. 2012;120(2 Pt 1):331-4.

20. Trompeter SE, Bettencourt R, Barrett-Connor E. Metabolic syndrome and sexual function in postmenopausal women. Am J Med. 2016;129(12):1270-7.e1.

21. Politano CA, Valadares AL, Pinto-Neto A, Costa-Paiva L. The metabolic syndrome and sexual function in climacteric women: a cross-sectional study. J Sex Med. 2015;12(2):455-62.

22. Esposito K, Maiorino M, Bellastella G, Giugliano F, Romano M, Giugliano $D$. Determinants of female sexual dysfunction in type 2 diabetes. Int J Impot Res. 2010;22(3):179-84.

23. Heidari M, Ghodusi M, Rezaei P, Kabirian Abyaneh S, Sureshjani EH, Sheikhi RA. Sexual function and factors affecting menopause: a systematic review. J Menopausal Med. 2019;25(1):15-27.

24. Mackness $M$, Mackness $B$. Paraoxonase 1 and atherosclerosis: is the gene or the protein more important? Free Radic Biol Med. 2004;37(9):1317-23.

25. de la Iglesia R, Mansego ML, Sánchez-Muniz FJ, Zulet MA, Martinez JA. Arylesterase activity is associated with antioxidant intake and paraoxonase-1 (pon1) gene methylation in metabolic syndrome patients following an energy restricted diet. EXCLI J. 2014;13:416-26.

26. Ng CJ, Shih DM, Hama SY, Villa N, Navab M, Reddy ST. The paraoxonase gene family and atherosclerosis. Free Radic Biol Med. 2005;38(2):153-63.

27. Mackness MI, Arrol S, Mackness B, Durrington PN. Alloenzymes of paraoxonase and effectiveness of high-density lipoproteins in protecting low-density lipoprotein against lipid peroxidation. Lancet. 1997;349(9055):851-2.

28. Aldemir M, Okulu E, Neşelioğlu S, Erel O, Ener K, Kayıgil Ö. Evaluation of serum oxidative and antioxidative status in patients with erectile dysfunction. Andrologia. 2012;44 Suppl 1:266-71.

29. Ciftci H, Yeni E, Savas M, Verit A, Celik H. Paraoxonase activity in patients with erectile dysfunction. Int J Impot Res. 2007;19(5):517-20. 